\title{
Mariano Latorre, Novelista Chileno Contemporáneo
}

(Continúa)

\author{
II. OBRA LITERARIA
}

Mariano Latorre es el escritor de la generación del 900 que ha trabajado con más unidad y continuidad en las interpretaciones campesinas. Es quizá el más vigoroso y el que ha profundizado con más energía en la pintura de ambientes exclusivamente chilenos. La literatura de Latorre es, pues, una literatura afecta a la tierra nativa; curioso es observar el hecho de que, guiado por ese afán de ser un retratista exacto del paisaje y de los tipos chilenos, hace anualmente largas excursiones a la zona central y sur de Chile, provisto de un cuadernito de apuntes, y se transforma en un repórter de los campesinos. Les habla en el sabroso lenguaje de los huasos, a los cuales imita maravillosamente, les interroga, les conversa. De esta manera se satura de su psicología y de su ambiente, y como sensual que es, recoge en su retina y en su oído las bellezas del paisaje campero y la riqueza expresiva del lenguaje criollo. De tal modo, emplaza convenientemente en sus medios naturales a los hombres que habrán de representar un tipo determinado en sus relatos novelescos.

La obra literaria de Mariano Latorre es extensa. Ha abarcado tres géneros literarios bien definidos: la novela, el cuento y los artículos de crítica literaria. Sin embargo, su valor primordial reside en su calidad de novelista y cuentista. 


\section{Cronologia}

La calendación de sus obras - novelas y cuentos- es la siguiente:

1912. Cuentos del Maule. (Contiene: "Un hijo del Maule"; "Sandías ribereñas"; "Orgullo ingénito"; "La risa de la gaviota"; "Don Zoilo"; "El jilguero de Miss Eliot”; "La canción perdida".) Santiago, Zig-Zag.

1918. Cuna de cóndores. (Contiene: "Risquera vana"; "La epopeya de Moñi"; "El tritunfo del chey"; "La cordillera es sagrada"; "Llolli y Cachuzo"; "Las pestañas de On Chipo".) Santiago, Imprenta Universitaria.

1920. Zurzulita. Novela. Santiago, Ed. Chilena.

1923. Ully y otras novelas del Sur. Novela. Santiago, Nascimento.

1926. Sus mejores cuentos. (Contiene, inéditos: "El Aspado"; "La desconocida". De Cuentos del Maule: "Sandias ribereñas"; "El jilguero de Miss Eliot". De Cuna de cóndores: "Risquera vana"; "La epopeya de Moñi"; "Las pestañas de On Chipo"; "El triunfo de Chey" ; "La cordillera es sagrada"; "Llolli y Cachuzo".) Santiago, Nascimento.

1926. I a confesión de Tognina. Santiago, (Revista) Lectura Selecta, Núm. 1, a. I.

1927. Collares. Santiago, (Revista) Lectura Selecta, Núm. 51, a. II.

1929. Chilenos del mar. (Contiene: "E1 llamado del mar"; "E1 finado Valdés"; "El piloto Oyarzo"; "En un vapor caletero"; "El pontón Núm. 5"; "Santiaguino en el mar"; "L'olor no más, On Benoist”.) Santiago, Imp. Universitaria.

1933. Hombres en la selva. Santiago, Editorial Zig-Zag.

1934. Ercilla, aventurero de la conquista. Santiago, Prensas de la Universidad de Chile.

1935. On Panta. (Contiene: "On Panta"; "E1 Aguilucho"; "Salteadores de Chillehue”.) Santiago, Ercilla. 
1937. Hombres y zorros. (Contiene: "Hombres y zorros"; "La vieja del Peralillo"; "Carboneros"; "La zorra bruja"; "Culpeo borracho"; "Sangre de cristiano"; "Domingo Persona"; "La chilla negra"; "Una astucia de Juan Sapo"; "Y este es Taquilla".) Santiago, Ercilla.

Tiene en preparación las siguientes obras: Mapu, Tierra de conquista, Diez relatos del tío Paciencia y, además, una novela sobre la explotación de la madera, que piensa titular: Raulies.

\section{Cuentos}

El temperamento narrativo de Latorre se manifiesta en el cuento. Alli se encuentran los elementos novelescos expresados con gran vigor y energía. Es el cuento narrado con la potencia vital del novelista.

En sus primeros relatos domina la tendencia regionalista, que el tiempo hará nacional y cíclica. Su propósito, como ya se ha dicho, es pintar todo Chile, desde la cordillera con sus arrieros y baqueanos hasta el mar con sus chilotés y maulinos navegantes y los indios del sur.

Como cuentista, la obra de Mariano Latorre es considerable. Ha publicado cuentos en Atenea, revista de la Universidad de Concepción, en La Novela Semanal, en Lectura Selecta, ambas de Santiago. Algunos de sus cuentos forman parte de capítulos de sus obras en colección, como ocurre con los dos cuentos: "La vieja del Peralillo" y "La tragedia de Taquilla", publicados, la' primera, en Atenea, abril de 1933, y la segunda, en agosto de 1936. Ambos cuentos están incluídos en su libro Hombres y zorros. $\mathrm{El}$ cuento titulado "El mar de los chilenos", publicado en la Historia de la literatura hispanoamericana de Zorrilla de San Martín, 1931, es uno de los que integran el libro Chilenos del mar.

El número total de los cuentos de Latorre, incluyendo los publicados en colección, asciende a 56 . Es muy posible que tenga un mayor número de cuentos publicados, pero no me ha sido posible determinarlo.

El tema de los cuentos publicados en revista es, como en casi toda la obra de Latorre, el país mismo: paisaje, tipos, costumbres, etcétera. No analizaré cada uno de estos cuentos, porque la obra más 
representativa de Latorre, constituída por sus cuentos en colección, está analizada en detalle más adelante. En ellos se observan sus características salientes como escritor criollista. La bibliografía que se incluye nos da una lista de las obras de este escritor.

"Algunos de sus cuentos de mar o de cordillera son verdaderas epopeyas, cuyos héroes son campesinos o marineros que luchan con las fieras o con las olas en un escenario lleno de épica grandeza". 12

En todos sus cuentos el protagonista es más bien la naturaleza: cerros, caminos, bosques y ríos. Se puede decir que aprovecha e1 relato como instrumento para transmitir a los demás su cabal conocimiento de la tierra chilena. Las descripciones ocupan casi la total extensión de sus relatos. El crítico Silva Castro nos cuenta en su libro Retratos literarios 13 la siguiente anécdota, al referirse al objetivo de su obra: "En 1930 sus compañeros de letras residentes en Santiago ofrecieron a Latorre un homenaje con motivo de su nombramiento de profesor en el Instituto Pedagógico. Al agradecer este agasajo, Mariano Latorre quiso condensar en pocas palabras la esencia de toda su obra. Confesó que su objetivo inicial había sido fijar en libros diversos los caracteres salientes del pueblo chileno. Dijo que lo habían preocupado todos los medios y todas las profesiones, y que la parte inédita de su obra estaba consagrada a seguir proyectando luz sobre otros aspectos de la vida nacional".

Como se puede deducir por la declaración que hace el propio Latorre, ese es el objetivo primordial de su obra: reproducir fielmente el panorama chileno. Ha recorrido paraje por paraje su provincia natal, Maule. Ha remontado el curso de sus ríos; ha escudriñado el bosque y la cordillera. Ha visitado, además, otras provincias, y penetrado en otros ambientes, siempre anheloso de documentarse. Todo esto encierra el contenido de sus cuentos.

La tierra chilena, llámese cordillera inaccesible o selva virgen, disuelve al hombre y lo hace minúsculo ante el prodigio del escenario. Como Latorre es un visual, un retratista, es lógico que su interés se vuelque más a la naturaleza misma que a la especie humana. Ha, pues, humanizado la naturaleza en sus obras.

Su primera obra se titula Cuentos del Maule, con la cual inicia su carrera literaria. Cuentos del Maule contiene seis cuentos: "Un hijo del Maule"; "Sandias ribereñas"; "Orgullo ingénito"; "La risa de la gaviota"; "Don Zoilo"; "El jilguero de Miss Eliot" y "La canción perdida". Todos ellos muestran diferente estructura y dimen- 
siones, pero coinciden en que son tuna exposición del paisaje y tipos chilenos.

Su autor escribió tal libro, siendo aún estudiante de Pedagogía, en "papel de estado", dejando vagar su imaginación en la vieja oficina del Instituto Nacional. 14

Este manojo de relatos se impuso por la agudeza y exactitud de la observación de la realidad y las evidentes dotes de animador literario del joven escritor. Hay un poco de romanticismo en sus páginas. Citaré algunos pasajes de prosa romántica que ilustrarán tal característica que se ha observado en el comienzo de sus narraciones. Su cuento "Orgullo ingénito", a pesar de que contiene espléndidas descripciones del paisaje criollo, es a la vez el estudio expositivo y costumbrista de una familia criolla de ascendencia española. En efecto, don Manuel María Lasso es el español radicado en Maule, con ciertos medios de fortuna, amasada por él mismo, que le permite vivir holgadamente. 'Tiene los rasgos del español:

Algo de la sangre del Quijote corría por sus venas de meridional, pero un Quijote más positivo, que comprende el valor del dinero en la tierra y le cree una palanca poderosa. Sólo la altivez desmedida del ilustre manchego persistía en él con fuerza irrefrenable, con soberana potencia.

(p. 9)

Don Manuel María vive con sus tres hijas, a las cuales trata en todo momento de imponer su carácter y voluntad. Es orgulloso, altanero, con un gran sentido del honor y de la caballerosidad. Altivo y digno en la concepción del trabajo, al cual ha dedicado los mejores esfuerzos de su juventud. Se ve, sin embargo, en dificil situación económica debido a malos negocios, pero por no sufrir la humillación de sentirse en la miseria y no ser bien considerado, como hasta ahora lo había sido por la gente de su pueblo, decide alejarse de allí, aun abandonando a su propia familia.

Este es un problema más bien de carácter psicológico que se plantea en el pequeño cuentecito. En este punto, Latorre como cuentista no ha sido bien juzgado por la crítica chilena, que muchas veces lo ha llamado "un escritor demasiado objetivo". A mi parecer, Latorre, en verdad, es un escritor objetivo, pero también en algunos de sus cuentos presenta casos de estudios de tipos humanos. El én- 
fasis, sin embargo, no está en el personaje humano que él analiza, sino en el paisaje. Le da más despliegue a la descripción que a la acción.

Prosa romántica, llamaríamos al siguiente pasaje del mismo cuento:

... si esas patedes cálidas pudieran hablar, qué de cosas dirían al que entiende el lenguaje de las almas que sufren y ansían querer, qué de hermosas confesiones de ensueños prisionetos; qué de profundas rebeldías contra la suerte que no tiende un mendrugo de placer a la vida que lo exige en la redondez de un pecho que se hincha o en el dulce vapor de ensueño que vela unos ojos" apasionados...

Las descripciones del paisaje maulino son muchas, como acontece en toda su obra:

En el río, el paisaje era diverso: la fuerza enorme de la corriente impedía el oleaje pequeño, formándose sólo largas ondulaciones, rápidas como cascadas, que daban al río perfectamente encauzado en su lecho natural, la apariencia de un enorme reptil...

En su cuento titulado "Un hijo del Maule" se cuenta la historia de un personaje importante: el abuelo. La forma de la narración es autobiográfica y da la impresión de que esta historia del abuelo sea la propia historia del abuelo de Latorre, contada por él mismo. Comienza la narración como sigue:

Después de la muerte de mi abuelo las cosas continuaron aparentemente como algunos meses antes; sin embargo, etc., etc. . .

Junto con anotar los rasgos sobresalientes del carácter del abuelo,

Es un placer para mí evocar la vida de mi abuelo en sus rasgos más hermosos; su amor al mar, su profundo conocimiento de las veleidades de aquel ierreno movible y traicionero sobre el cual echaba sus lindos edificios de velas, de bello casco blanco y complicada arboladura. Mi abuelo era hombre de acción y provisto de una audacia llena de voluntad.

Su concepción de la amistad era casi abnegada: no habría dejado perecer de hambre a un amigo, si en sus manos hubiera estado el socorrerlo. 
el cuento nos presenta una serie de pasajes ricos en descripciones de la región :

Al llegar de nuevo al Maule, me pareció despertar de un sueño: todo iba apareciendo en $m i$ con relieve admirable, con límpido tecuerdo: cada cosa era una nota distinta. Recordaba las casitas modestas y negruzcas, vestidas como lugareñas, con sus ventanas cuadradas, en que era necesario para abrirlas corter hacia arriba con chirriante dificultad la mitad de ellas; y apoyarla en un pedacito de madera. . .

Además, se encuentra explicada la historia del Maule, junto a páginas de gran belleza lírica:

El ansia interior, el desordenado lirismo de mi alma había concluído por fatigarme horriblemente, echando sobre mí, como un velo de ensueño, un adormecimiento sedante como el del opio, en el fondo del cual rugía el mar con cólera espumosa.

Hay también algunos pasajes en que se vislumbra un fondo de crítica social; por ejemplo, al referirse a la transformación de su pueblo en el Maule, dice:

Luego se construye el ferrocartil y una heterogénea población venida de todas partes de Chile transformó la quietud aldeana del pueblo, dormido con sus casuchas achatadas a la orilla del agua, envuelto en el aire frescachón, salpicado de agua salada, que el viento del sur roba del océano. Nunca me cansaré de criticar la influencia perniciosa de ese gentío exótico sobre las costumbres de mi tierra: ella ahuyentó a los marinos antiguos, mató a los guanayes y corrompió al pueblo bajo...

$\mathrm{Y}$ así todo el cuento está saturado de informaciones regionales de las costumbres de la tierra misma.

Otro cuento muy bello de esta misma colección es el titulado "Sandías ribereñas". Se cuenta la historia de una familia de campesinos que viven en un fundo cercano al Maule. Rosario es la protagonista de este sencillo cuentecito. Es una campesina robusta, sana, que ha crecido en la vida campestre. Su alma es ingenua y candorosa. Su padre, "el taita", decide que su hija colabore en la tarea de alivianar la pobreza en que viven. Para esto, y aconsejado por 
Doña Rosa (mujer dueña de una taberna en el pueblo, especie de Celestina del lugar, quien trata de acapararse a todas las jóvenes para dar más atracción a su negocio), el viejo convence a Rosario de la necesidad de salir del fundo para ir a trabajar al pueblo. A1 principio la muchacha se resiste. Tiene miedo de abandonar su pedacito de tierra:

Allí en el fondo de su corazoncito medroso de bestiezuela arisca lloraba la queja dolorida: Yo no me quiero d'ir, paire!

En el alma de aquella campesina se plantea el eterno problema del miedo a lo desconocido, del terror que produce la ciudad, centro de corrupción y de maldad, y del presentimiento de que ya no seguiría siendo la misma buena campesina ingenua de la región :

Acaso presentía que se alejaba para siempre de su choza Sería sólo la nostalgia del tordo de los boldales encerrado en una jaula o la pena salvaje del zorrito arrancado de las serranías?

\section{E1 mismo Latorre contesta:}

Era el sabor de la tierruca, el hambre de la tierra y de las costumbres; era que ella habia nacido para vivir y caer en la misma tierra como los árboles o las sandias del sandial de On Gómez.

(p. 73)

Rosario se va del fundo ese verano y sucede lo inevitable. No vuelve más. Después de algunos días de trabajar en la taberna conoce a Cenobio 'Donoso, tenorio de profesión y amigo de Doña Rosa, y se va con él. Las páginas del cuento dicen:

Se iba para siempre del pueblo, volvería a pasar de nuevo frente a su montaña pelada, pero ya para no volver más a subir el camino blanco y polvoriento que conduce al río; thabía olvidado por completo su pasado y su cuerpo lleno aún de salud iba a seguir alimentando el apetito de los hombres de la ciudad, porque una ley fatal la empujaba sin que nadie pudiese impedirlo nunca. No estaba la vida constituida de ese modo? De las sandías del sandial, no quedan algunas en la orilla para que la especie no perezca y las más robustas no van a la ciudad? 
Rosario cumplía fielmente su misión. Ella era de las fatales. Estaba destinada a la ciudad y no a perpetuarse en la vida del campo.

Doña Rosa tendría otra campesinita al verano siguiente, otro ciento de sandías y otro amigo de la señora se encargaría de enamoratle la muchacha y traerla a la ciudad. Es la ley ineludible donde la vida tiene un tinte de tan salvaje primitividad.

Así el cuento de la pobre china del campo, fresca y sabrosa como una sandía, pero que al contacto con la ciudad se estropea lo mismo que esas sandias maduras que se desprecian porque ya no sirven...

El ambiente es el campo, expresado con gran relieve y amor al paisaje del Maule; hay también en este cuento algunas escenas descritas que reflejan el carácter costumbrista del escritor:

$\therefore$ Alli se ven toda clase de escenas de costumbres: un botero que duerme una mona bajo el parral diminuto, una vieja que despioja a una hija con un bofetón cuando la mocosa se mueve, un carpintero que construye un bote y cuyas costillas se muestran en toda su desnudez o un muchacho de rojiza piel que se zambulle sobre el agua tranquila, completamente en pelota...

Essta escena costumbrista es netamente criolla, del campo nuestro, y especialmente de la región del Maule que el autor describe.

Su segundo libro de cuentos es Cuna de cóndores. Constituye esta obra una magnífica toma de posesión de los Andes para nuestras letras. Tanto en el citado volumen como en sus Cuentos del Maule, Latorre se reveló como un maestro en las descripciones de los paisajes y de las cumbres cordilleranas en la actual provincia del Maule. Esta colección de cuentos incluye: "Risquera vana"; "La epopeya de Moñi"; "Las pestañas de On Chipo"; "El triunfo de Chey"; "La cordillera es sagrada"; "Llolli y Cachuzo".

En todos los anteriores cuentos se pinta la vida agreste del país con minuciosa fidelidad. El autor describe también las penas y los placeres del habitante de la cordillera, el pastor y el arriero y aun el bandido que busca refugio en sus complicados callejones, apremiado por la ley, en demanda de la pampa.

Olvidándose de si mismo, el autor cuenta todo lo que sufren y sueñan, quieren o piensan sus personajes, y como la psicología de 
estos personajes es simple, la visión que nos da es precisa y clara. Allí aparece el roto cordillerano en su lucha con los elementos hostiles, en un escenario sobrecogedor por su grandeza y su bárbara inclemencia.

Los cuentos de Cuna de cóndores son relatos impersonales, en los cuales se describe una anécdota o una vida humana más o menos completa, sin que intervenga su persona en la tragedia misma ni en la elaboración del relato.

E1 cuento "Risquera vana" presenta como tipo al "bandido", al hombre del campo que se transforma en vagabundo y aventurero. Este es Nicomedes Román. Dice al referirse a él:

Su vida era una vida de lance; vida de perro de presa, instintiva, cruel, vida de lucha en que había que grunirir y mostrar los dientes para alejar al enemigo que llegaba a disputarle la hembra o la ganancia del monte, base económica de su vida de vagabundo.

(p. 89)

Otro tipo interesante que se describe en el mismo cuento es el de una mujer: Florinda, la moza campesina a cuya casa llega el bandido en su afán de buscar un refugio tranquilo, y a la vez un escondite para su vida de eterno perseguido por la ley. E1 bandido se siente a sus anchas en el rancho de Florinda y de su madre. La moza de la sierra siente nacer en su aima una admiración secreta por el hombre aventurero y le escucha ensimismada los relatos maravillosos de su vida andariega. Esta secreta admiración se va transformando poco a poco en afecto. Va despertando la hembra al contacto del hombre que ha aparecido repentinamente en su vida solitaria y apacible. Su madre, sin embargo, con la intuición propia del conocimiento de la especie humana, no cesa de repetirle la siguiente advertencia, cargada de experiencia:

-Cuidao, Florinda, los guainas son como risqueras vanas, por juera parece que no hubiera ná, y aentro hay escondio un zorro.

(p. 104)

Aquí está encerrada la filosofía simple, pero profunda, de esta vieja del campo.

Paralelo al desarrollo de esta historia del bandido y de sus andanzas, hay pasajes descriptivos del paisaje maulino: 
A medida que avanzaba, reconocía el camino con ese instinto maravilloso del hombre de campo. El sendero corria como un arroyuelo caracoleante al pie de un murallón de enorme base, alfombrado hasta la cumbre de retorcidos michayes verde-oscuros: detrás cantaba el Melado que nace de los ventisqueros de un volcán, cuyo cono nevado se levanta por encima de aquel mar de cumbres y desagua en el. Maule su caudal puro y espumante. Alli las cumbres se amontonan pegándose unas en la espalda de las otras; y uniéndose irregularmente entre sí como las nubes de un movible cielo de tormenta, y el río se retuerce en el fondo del precipicio, con ruido sordo y lejano... etc.

(p. 91)

En "La cordillera es sagrada" hay descripciones de color y dramatismo:

La montaña se arerca poco a poco. Los filos azules de las colinas se tornan verdes; las sombras cenicientas de las quebradas descubren las blancas torrenteras de plata; y las venas grises que rayan las cresterias lejanas blanquean al sol. Se aprieta la irmensa cordillera como un puño cerrado; una vida formidable palpita bajo el raso transparente de los cielos. Corren las montañas en persecución de las aguas en fuga y en la boca abierta de los cajones se espesa el cielo sereno en una perlina humareda azulosa.

En otras páginas exclama:

La sierra es sagrada, Dios la protege y la ampara.

Los personajes de sus cuentos en Cuna de cóndores, On Chipo, On Nicomedes, Florinda, son el producto de la sierra. Todo ondula, todo se mueve en su pintura colorida.

En 1929 publica su nueva colección de cuentos, Chilenos del mar, que incluye los siguientes cuentos de la vida marítima criolla: "El llamado del mar"; "El finado Valdés"; "E1 piloto Oyarzo"; "En un vapor caletero"; "El pontón Núm. 5"; "Santiaguinos en el mar"; "L'olor no más, On Benoist".

En estos cuentos se nota una tendencia especial del escritor, y es que se entromete vivamente en las narraciones; trata de interpretar los elementos humanos que intervienen en sus relatos.

En Chilenos del mar nos lleva a conocer a los hombres que viven en la proximidad del mar y que sobre él basan el esplendor o la miseria de sus existencias. 
Chile, como país dotado de una extensísima costa, es un pueblo de marineros. Hay por lo menos dos regiones en que la influencia del mar sobre la tierra es visible y preponderante. Maule, la patria del autor, es una; Chiloé es la otra. De allí, principalmente, son estos chilenos del mar. El autor no se ha dejado dominar ahora por su amor a la naturaleza. Ha preferido narrar la humilde tragedia de un botero antes que cantar la cólera salvaje del océano.

Chilenos del mar es una valiente exploración por los canales del sur y el mar libre, donde el hombre, el episodio y la naturaleza se unifican admirablemente.

En esta colección de cuentos se destaca "El finado Valdés" por el carácter de análisis psicológico que tiene. Es el relato de una vida apagada, quieta, mínima, descolorida, que irrumpe de pronto en una transfiguración extraordinaria, llena de color y dinamismo y que se multiplica en un sinfín de aventuras que no caben en su vida y culminan con su muerte repentina.

Juan Valdés, alias "El finado", era empleado del Ministerio del Interior. Vivía en una pensión de la calle Nataniel. De pronto, Valdés desaparece y nadie sabe de su paradero. Se dice que se fué al Sur y allá terminó su vida. El autor nos leva entonces a averiguar el paradero de este hombre. Nos hallamos en la casa de pensión para preguntar algunos datos sobre tan interesante y misteriosa personalidad. Hablamos con la dueña de la casa; y tenemos a Latorre, costumbrista :

Sus ojos grises, sin brillo, me miraron un segundo distraídamente. Sin saber por qué la vida entera de la casa de pensión, con sus comidas sin sustancia, sus muebles viejos, su frialdad, pasó por mi ce-. rebro en rápida visión al ver su gesto cansado y flojo.

En el afán de seguir los pasos de Valdés, el autor nos lleva a visitar el bar alemán de la calle San Diego, en donde generalmente el personaje acostumbraba pasar las tardes. Toda la existencia de Valdés pasaba ante los ojos del autor, mientras nos situamos en el bar alemán:

La vida monótona de este hombrecillo descolorido se desarrollaba ante mí como una película. Penetraba sus costumbres, sus predilecciones, sus vicios mediocres. Algo de espectral había en su existir 
anónimo, sin dejar más rastros que la sensación de su flacura y la materialidad de sus gestos.

Frente a su mesa de trabajo copió las mismas notas y en este bar alemán bebió todas las tardes su cerveza. La vida pasaba junto a él, cambiante o fugaz, y él sub́sistia, sin embargo, inmutable. Había una fuerza en eșta monotonía. Los jefes mismos lo aceptaron sin protesta como se acepta algo que no se puede remediar. El hábito lo había impuesto, haciéndolo parte integrante de aquella oficina del Ministerio. $\mathrm{Ni}$ una idea, ni un impulso. No despertaba antipatía, ni simpatía. Ni buenos ni malos para él jefes y compañeros. Sus amistades no existían. Apenas era un hombre...

(p. 70)

En las anteriores líneas está expresada la psicología del protagonista de este cuento, que más que cuento es un verdadero estudio de psicoanálisis.

Se continúa después la descripción de todos los actos de la vida de este hombre, su ingreso inesperado en una Comisión Arbitral que el Gobierno enviaba al Sur, su actuación brillante ante un problema de huelga, brillante quizá porque actuó con la inconsciencia de la improvisación :

El fué quien rompió el hielo entre la Comisión Arbitral y los obreros revoltosos; él quien los tranquilizó convenciéndolos que debían aceptar las proposiciones de la Compañía.

Luego el desaparecimiento de esta vida curiosa:

No sé si por taras hereditarias o potque su físico endeble no pudo resistir la movilidad de esta vida nueva, el thecho es que ardió su espiritu como un puñado de aristas en las llamas y como un puñado de atistas se extinguió igualmente.

Los otros cuentos de la colección tienen como escenario el mar y la vida marítima. Sus protagonistas son marinos. En el cuento titulado "El pontón Núm. 5", nos da Latorre una visión de estos navegantes :

Eran marinos de alma, de vocación: el mar, sobre todas las cosas; los barcos, viejos amigos inalterables.

(p. 151) 
Luego, Latorre personifica a los mismos barcos y los supone aun poseedores de alma:

A pesar de sus proas mochas, de sus planchas carcomidas, del lustroso polvo de carbón que chorreó sus cubiertas y los muñones de sus palos, tenian un alma, una vida digna de respeto.

(p. 151)

El mar juega también un papel importante en tales cuentos marinos:

El mar daba la impresión de tragarse ávidamente todo germen de sonido, todo signo de vida que se produjese en su inmóvil superficie: las voces humanas, el pito de un vapor, el grito repentino de una sirena o el graznido de las gaviotas a quienes despertaba, en las boyas, el tac tac de un motor que regresaba al muelle.

En 1926 aparece una antología bajo el título de Sus mejores cuentos. Tal colección contiene dos producciones inéditas tituladas: "E1 Aspado", "La desconocida". De Cuentos del Maule: "Sandías ribereñas", "El jilguero de Miss Eliot". De Cuna de cóndores: "Risquera vana", "La epopeya de Moñi", "Las pestañas de On Chipo", "El triunfo de Chey", "La cordillera es sagrada", "Llolli y Cachuzo".

En 1934 se publica "Ercilla, aventurero de la conquista", ensayo que desgraciadamente no he leído. Es curioso también que en los estudios sobre las obras de Latorre no he encontrado referencia alguna a tal trabajo.

En 1935 aparece On Panta, que contiene, además del cuento "On Panta", "Salteadores de Chillehue" y "E1 Aguilucho".

En esta colección de cuentos sobresalen tres aspectos bien característicos:

a) E1 descriptor minucioso, casi fotográfico en "Salteadores de Chillehue", con una marcada nota realista:

El cadáver fué sentado en el suelo. La cuadrada cabeza, de un color mate y exangüe, se partía en una carcajada de trágica mudez. Las mandibulas se abrieron en la agonía y alcanzaba a advertirse el paladar rojo y las dos hileras de poderosos dientes, en una feroz actitud de morder. Los ojos descansaban semi-entornados.

La cita anterior se refiere al zapatero de Chillehue, famoso bandido de esa comarca campesina. 
El autor explica el significado del nombre de su cuento:

La mina de oro que mi amigo bautizó con el nombre de "Chillehue" porque las quebradas hervian de chillas montaraces, era una ventana abierta al paisaje, a media falda de un cerro.

b) El criollista y estilista en "On Panta", que narra la historia de Don Pantaleón Letelier, el viejo campesino de las montañas maulinas. El cuento tiene bellas descripciones de paisajes, del deporte de los cerros; el zorrear, deporte favorito de On Panta, escenas de la vida campestre, etc. Dice el autor al referirse al Maule:

Mi paisaje maulino no había cambiado gran cosa. Me resultaba más pobre, si cabe, idealizado por la lejanía y el recuerdo. Las mismas jorobas gredosas donde sólo los romerillos entierran sus raices pertinaces. Las mismas quebradas que cubren obscuros boldos y claros maitenes, junto a un hilillo de agua. $Y$ los mismos ranchos que patecen brotados de la tierra gris como los árboles y las hierbas, en tal forma se han coloreado con el matiz de la piedra y del terreno.

c) Y el poeta en "E1 Aguilucho", en que se advierte un marcado lirismo. La nota lírica se puede ver expresada en el pasaje siguiente:

Alrededor del aguilucho agonizante, sólo vibraba la sordina de miles de abejas que volvian de nuevo a las flores de primavera. Era la época de las semillas y de los almácigos. Los pájaros audaces caían en racimos sobre las eradas de cebollinos y betaragas.

Este cuento de apenas tres páginas es, como lo subtitula el autor, un "intermedio agreste".

Su último libro, Hombres y zorros, es una colección de diez cuentos a cuyo través Latorre se revela como seguro poseedor de sus mejores cualidades. Perdura en él su milagrosa objetividad, su calidad sensorial que le permite deleitarse hasta el éxtasis con las revelaciones del mundo visible y audible. Como siempre, se ha documentado pacientemente, estudiando la región y los personajes; y la comarca ha pasado viva y palpitante al libro. Su primer cuento lleva el nombre del libro: "Hombres y zorros". Descripciones de su pro- 
pia tierra, el Maule, como la que se anota a continuación, en que el propio autor parece compenetrarse con el sentido exacto de la transformación que se va experimentando en esa región campesina:

Cerro, aldea, río y estero, un Chile en síntesis, donde vivían zorros astutos que husqueaban burlones en las noches, robándose gallinas y cabritillos y que en las primaveras poblaban el monte con el alarido de sus ruidosos amores. Comprendí a mi rincón. Le encontré un sentido oculto a esas piedras y a esos zorros y a esos hombres que vivían junto a ellas.

Luego, expresa la compenetración de los animales con el ser humano:

El animal comunica al hombre el secreto de su vitalidad, y el hombre al animal, los recursos de su inteligencia.

y en otros pasajes de su cuento, revela el autor su calidad de sentidor del paisaje:

Mis sentidos bebían el paisaje con infantil arrobo.

Lineas llenas de belleza lírica y al mismo tiempo de interpretación de la naturaleza criolla:

Supe de veranos, maduros de luz, y de inviernos, aullantes de vientos y de lluvias.

$$
\text { (p. 9) }
$$

"La vieja del Peralillo" es otro cuento de esta colección. La protagonista es Doña Bonifacia Retamales de Aravena, del Peralillo, Doña Moñi, como la llamaban familiarmente en la montaña. Es una recia figura de mujer, brava, sensual, apasionante; dominaba a sus maridos y amantes y los hacía trabajar como peones, a chicotazo limpio. Latorre la describe:

Cínica y audaz, sin pudor ni remordimientos. Símbolo de la hembra campesina, pasiva y sin conciencia como la tierra misma. Como ella, fecunda y eterna. 
La historia trata de la muerte de tal mujer, y de los comentarios que hacen los demás personajes del cuento, todos ellos campesinos, o mejor dicho "huasos", sobre la vida de esta aldeana bravía y pecadora; hay descripciones del velorio, costumbre folklórica de nuestro pueblo, luego el entierro, la reunión de los huasos en la iglesia, etc. Todo descrito con gran coior y realismo.

Uno de los huasos dice, al referirse a Doña Moñi:

- ¿Tú sabías que Doña Moñi murió en el suelo, porque en la cama habia pecado mucho?

(p. 26)

La reunión de los huasos frente a la iglesia para dirigirse al entierro nos da la visión de una típica escena costumbrista de nuestra yida del campo:

Todo el pueblo se reunió en el árido solar que hacía de plaza. Los huasos se habian sacado trabajosamente sus viejos y estrafalarios sombreros y las crenchas se esponjaban, cambiando visiblemente de forma a cada segundo.

(p. 47)

Parece que el autor mismo asistiese como espectador a todos estos acontecimientos que suceden en el pueblo de montañeses:

Iba de asombro en asombro. A pesar de mis recuerdos de la montaña, todo era, para mí, de un extraño sabor primitivo. Parecía vivir en otra época. En lejanos tiempos coloniales.

Más adelante nos da la interpretación de las gentes de la montaña $\mathrm{y}$ de sus costumbres:

Las supersticiones heredadas de los antepasados españoles y desfiguradas por los indios al civilizarse, habian persistido casi sin cambiar. Todas ellas tenían un mismo fin: hacerse gratos a Dios en el momento de abandonar la tierrą.

Los demás cuentos de la colección: "Carboneros", "La zorra bruja", "La chilla negra", "Domingo Persona", etc., contienen también espléndidas interpretaciones regionales. 


\section{Novelas}

Como novelista ha cultivado con invariable constancia la narración basada en la vida intensa de nuestras cordilleras, costas y montañas. Ha sido, por ello, el creador de una literatura nacionalista de innumerables matices y conscientemente arquitecturada. Latorre, junto a su vigoroso poder narrador, posee cualidades de refinado estilista. La sobriedad de expresión y la justeza de imágenes añaden relieve al relato.

Zurzulita y Ully constittyen su producción novelada. Analizaremos a continuación las dos novelas.

Zurzulita, publicada en 1920, tiene toda la riqueza que puede aportar el novelista en cuanto a su capacidad de narrador y a su talento artístico. Es, además, una novela esencialmente chilena, de nuestro campo del valle central de Chile. Las descripciones de la vida campesina, de los tipos, de las costumbres, están elaboradas con gran exactitud. Son auténticas. El autor ha traspasado a las páginas de la citada novela todo el producto de sus observaciones directas, vividas entre esta gente del campo de Purapel. Los tipos se hallan fielmente pintados, con gran relieve. Mateo Elorduy, el nuevo dueño del fundo de Millavoro, es un romántico; más aún, es tun sentimental que no entiende nada de las cosas del campo, pero que decide quedarse en Millavoro, porque se ha enamorado profundamente de Milla, la campesina que es maestra de la escuelita rural de Millavoro. En sus sueños, Mateo compara a Milla con las "zurzulitas", o sea las tortolitas de las montañas. Enctentra que "hay algo de huraño y suave al mismo tiempo en la preceptorita rural, como en la tortolita de las umbrías". 16 A Milla le gusta chupar la goma dulce y aromática de los cógutiles, la misma que le sirve de alimento a las zurzulitas. Milla es seria y apasionada. Dicen los campesinos que su nombre significa oro y que Milla desciende, por su tatarabuelo, de un valiente soldado español. A pesar de ser rústica tiene una extraña clignidad en apariencia y carácter, que la hace aparecer como una persona superior al medio en que viven los habitantes de Millavoro. $\mathrm{Su}$ padre es un pobre ciego y su hermano Quicho está habilmente pintado con toda la malicia y bondad que hay en el chiquillo del campo. Otro personaje, casi grotesco por el realismo con que lo descri- 
be Latorre, es Samuelón, el pobre idiota que vagabundea por el campo:

Era una cabezota enorme: una masa de barro oscuro de colgantes pliegues, en que un profano hubiera tenido la intención de modelar là cara humana; la viruela había agujereado despiadadamente la cara, dándole la apariencia blanducha de una esponja; producía la impresión de que tocándola con el dedo se iba a hundir; un bosque de pelos tiesos, opacos de caspa, asomaba por entre las orejas, despegadas del cráneo; el resto del cuerpo, apenas cubierto con harapos sebosos, no tenia importancia; se evaporaba ante la macrocefalia del cretino.

Samuelón tenía el hábito de hacer pelear a sus dos manos. Tenía la obsesión de que sus dos manos eran dos toros y los llamaba el Trapi y el Manqui. Se ponía en cuatro pies en la tierra y comenzaba a arañar el suelo con sus dos manos, los ojos se le salían de sus órbitas debido a la excitación que le producía esta pelea de toros, como decía el idiota. Seguía arañando la tierra hasta dejarse las manos sangrando, en medio de la risa de las personas que lograban ver1o. La escena de la pelea del toro imaginario está descrita con gran minuciosidad de detalles y con tal realismo, que al leerlo nos produce una especie de escalofrío:

Los pulgares deformes, semejantes a raíces de robles, se separaban con extraña vida del resto de las manos; colocados a cierta distancia representaban a los dos tozos que medían sus fuerzas antes de cruzar sus testas enfurecidas. Los rugidos se hicieron más airados, más apremiantes. La lucha que reproducian sus dedos también lo enfurecía: gotas de sudor resbalaban por los pliegues duros de la piel; una saliva espumosa barnizaba sus labios. Por fin se efectuó el encuentro: los pulgares llenos de tierra, se arañaron despiadadamente entre bramidos salvajes. . etc.

La idea fija en la mente del idiota era esta pelea de sus manos en que "el Trapi mañero, que' Samuelón llevaba impreso en su tosca mano simbólica, vencía eternamente, en la manada salvaje, sobre el Manqui inexperto". 17

On Carmen es el prototipo del huaso astuto y malo, aprovechador y "mandón". Se consideraba el verdadero "cacique" o dueño de Millavoro y su influencia como hombre quería dejarla sentir en el 
control de la hacienda y en las campesinas del lugar, especialmente a Milla, por quien sentía una atracción especial. Era agresivo, envidioso y pendenciero. Vengativo, como es el hombre del campo chileno, cuando cree que alguien se entromete para estropear sus asuntos.

Mateo siente crecer su afecto por Milla. Le atrae enormemente el cuerpo de la muchacha. Una tarde la posee en el bosque en medio de los cóguiles de maqui y la campesina se le rinde con entera sumisión. Viven por algunos meses este sueño de amor para el espiritu de Mateo. Sin embargo, en Milla se opera una transformación. Siente una extraña antipatía, un alejamiento por Mateo, a pesar de que va a ser madre. Extraña psicología que expresa la rusticidad de la mujer campesina en cuanto a sus sentimientos. El novelista describe tales dudas de la muchacha muy fielmente:

E1 espíritu del joven no había penetrado en su espiritu: solamente sus cuerpos se unieron sugestionados por el imán de la juventud y bajo el influjo de la tierra y del aire. Su pereza, su sentimentalidad, la ausencia del espíritu de lucha que la pasión había borrado aparecian ahora claros; no eran esos atributos masculinos para su alma ruda de campesina que prefería la realidad presente al mañana inseguro. Nació en ella un extraño desvío por el macho, una repugnancia instintiva por las cosas del sexo. La vida que empezaba a germinar dentro de su cuerpo, que rasgaba poco a poco sus carnes, haciéndola más pesada, más fuerte, llegaba también a su cerebro aferrándolo al terruño, suavizando las asperezas del medio primitivo, las mezquindades del diario vivir.

(p. 258)

Mateo quiere casarse con Milla y llevársela fuera de Millavoro. La campesina lo rechaza con palabras duras, con indiferencia.

En el desarrollo de esta novela, que termina en tragedia, hay interesantes descripciones de una fiesta en la escuela del campo, con canciones de corro de niños, comidas típicas campesinas; Iuego viene el relato del velorio de Pituto, el niñito de On Varo, otro huaso del fundo. La vendimia y la fiesta de San Francisco, son aportes del escritor para completar el riquísimo cuadro folklórico que nos da la novela.

También figura allí la venganza de On Carmen, que no puede olvidar la ofensa de Mateo, "el entrometido", como lo llama, porque Mateo ha reñido con él, derrotándolo, y además le ha arrebatado el amor de Milla. On Carmen lo hace matar cobardemente, en un re- 
codo de la selva solitaria. Mateo no aparece en muchos días. Nadie sabe de él: la justicia no se practica en el campo. Todo se hace silencio. Enmudecen los habitantes. "Ser mudo y sordo era el tácito acuerdo de los ranchos, cuando se trataba de alguna de estas venganzas, en que un caciquillo de aldea era el protagonista". 18 Milla presiente el crimen y corre a buscarlo a la selva acompañada de Quicho. Los jotes de Millavoro le sirven de guía para mostrarle la ruta en donde se encuentra el cuerpo exánime de Mateo.

Zurzulita representa un valioso esfuerzo de la literatura nacional. Es un libro como pocos se escriben en nuestro medio, admirable por su prosa de expresividad cabalmente eficiente, por la riqueza folklórica que contiene, por el lenguaje típico de los huasos y porque el autor se muestra hondo conocedor del medio campesino.

Ully y otras novelas del Sur, publicada en 1923, contiene, además de la novela $U l l y$, cinco cuentos cortos titulados: "Un hombre", "E1 perro de On Polo", "La muerte del cuclillo", "Whiskey and Ginger Ale" y "Vuelve por un queso".

Ully nos presenta un cuadro de la vida provinciana del Sur de Chile, región colonizada por los alemanes. Ully es el nombre de la protagonista, una figura de muchacha rubia y tierna; es la alemancita ingenua que vive un ensueño de amor breve que se disipa casi al nacer.

Ully fué premiada en un concurso organizado por El Mercurio, de Santiago; los otros cuentos aparecieron en la revista chilena Pacifico Magazine.

Emilio Labarga, un pintor joven y de carácter un tanto romántico, va a pasar unas vacaciones de verano al Sur de Chile, a un fundo cerca del Lago Llanquihue. Alli se aloja en casa de su amigo, un alemán llamado Carlos Stolze. Carlos tiene una hermana, Ully, por quien nuestro pintor siente nacer un profundo amor. Ully también, en medio de su candorosa ingenuidad, se va enamorando de este joven hasta que una tarde Emilio le confiesa que él es casado y que tiene que marcharse; que ella le ha simpatizado vivamente por su frescura juvenil y la sencillez de su alma bondadosa, pero que hay un impedimento entre esa amistad que él no quiere enturbiar. La novela tiene muchas observaciones de psicología germana y criolla; hay también escenas de costumbres del lugar, como la celebración de unas bodas, la misa de la aldea, descripciones de las casas-chalets de este pueblito que, como varios de los del Sur de Chile, está coloni- 
zado por alemanes. Intercala frases en alemán dichas por la pequeña Ully, que está despertando a la vida de mujer, pues apenas cuenta con 16 años.

Emilio Labarga se enternece al oír la misa de la aldea:

Por primera vez una misa le produce una emoción que no acierta a explicarse, pero que lo conmueve, lo conforta, lo hace olvidarse de la incertidumbre de su vida. Es una fe tan sincera, tan hondamente tecogida la que respira este cuadrado de tablas de lingue, erguido sobre la colina, donde antes la selva levantaba sus columnas seculares.

(p. 54)

Trátase de una novelita de apenas sesenta páginas, pero de tema muy interesante por su sencillez.

\section{Articulos}

I,os artículos de crítica literaria escritos por Mariano Latorre han sido publicados en: Atenea, Anales de la Universidad de Chile, Pluma" y Lápiz, Revista de Artes y Letras, Chile Magazine, La Información y Zig-Zag, revistas literarias de Santiago de Chile. He leído solamente los artículos de crítica literaria publicados en Atenea y en los Anales. Tengo conocimiento de los demás artículos, por la bibliografía recogida. (Véase la "Bibliografía” de este trabajo.)

Los artículos versan sobre literatura española, hispanoamericana y extranjera. Entre los artículos de literatura extranjera, tiene estudios sobre novelistas norteamericanos como J. O. Curwood, Bret Harte; ingleses como D. H. Lawrence y Joseph Conrad; noruegos como Hans Kink y Peter Ëgge. También ha escrito estudios críticos sobre Spengler y Camilo Lemonnier.

En la opinión de los críticos, Latorre ha leído con especial detenimiento a los escritores extranjeros nombrados y algunos dicen que sus obras presentan aspectos similares a las obras de ellos (Silva Castro). Habría que leer las obras de tales escritores para determinar hasta qué punto el novelista chileno ha sufrido la influencia suya, pero las dimensiones del presente trabajo no nos permiten profundizar en el citado aspecto.

Entre los artículos que se refieren a literatura hispana (hispanoamericana y española), podemos nombrar estudios sobre Pío Ba- 
roja, Valle-Inclán; Gregorio Sánchez Gómez, novelista colombiano; Mariano Azuela, mexicano; Coelho Netto, brasileño; Samuel A. Lillo, Blest Gana, chilenos, y varios aspectos de la novela americana en general. Por las referencias bibliográficas obtenidas, podemos afirmar que Latorre empieza a escribir artículos de crítica literaria en 1912, o sea el mismo año de la publicación de su primera obra Cuentos del Maule. Estos artículos son publicados en Pluma y Lápiz. Desde 1926 a 1929 la revista La Información publica trabajos de Latorre en cada uno de sus números, artículos de que tengo conocimiento por medio de la obra de Silva Castro titulada Fuentes bibliográficas para el estudio de la literatura chilena, 1933. Los títulos de tales artículos pueden verse en la "Bibliografía" del presente estudio.

En todos estos artículos de crítica literaria ha seguido el método científico, o sea el que se basa en el examen de los documentos. No hay juicios a priori. Todos ellos son producto de un profundo conocimiento de la materia y de un detenido análisis. Procedimienta discursivo con tendencia filosófica.

(Continuará)

Magda ArCF

12. Samuel A. Lillo, Literatuta chilena, p. 442 .

13. Raúl Silya Castro, Rettatos literarios, p. 123.

14. J. García Games, Cómo los he visto yo, p. 137.

15. Silva Castro, op. cit.

16. Zutzulita, p. 67.

17. Zutzulita, p. 178.

18. Zutzulita, p. 261. 
